\title{
Synthesis and Application of Thiosquaramides and Their Derivatives: A Review
}

\author{
Sándor Nagy ${ }^{1}$ Péter Kisszékelyi1 ${ }^{1}$ József Kupai ${ }^{1 *}$ \\ 1 Department of Organic Chemistry and Technology, Faculty of Chemical Technology and Biotechnology, \\ Budapest University of Technology and Economics, H-1521 Budapest, P.O. Box 91, Hungary \\ ${ }^{*}$ Corresponding author, e-mail: jkupai@mail.bme.hu
}

Received: 15 July 2018, Accepted: 30 September 2018, Published online: 05 November 2018

\begin{abstract}
Thiosquaramides are the thio analogues of squaramides that are widely applicable in the fields of asymmetric catalysis, pharmaceutical research, and chemical biology. Having four-membered ring system derived from squaric acid, thiosquaramides are feasible hydrogen bond donors and acceptors. A high affinity for hydrogen bonding is driven through a concomitant increase in aromaticity of the ring. In this review the structural properties, acidity, and lipophilicity of thiosquaramides and squaramides are compared. Different synthetic procedures starting from squarates, half-squaramides or squaramides are shown, and the main derivatization methods are outlined. Finally, the yet only few applications of this interesting family are reviewed. Considering their hydrogen bonding and aromatic switching, in combination with structural rigidity, they bear the possibility of becoming robust and tunable bifunctional organocatalysts for a range of synthetically useful transformations in the future.
\end{abstract}

Keywords

thiosquaramide, squaramide, hydrogen bond donors, organocatalysis, anion transport

\section{Introduction}

The preparation of urea was an important conceptual milestone in organic chemistry. Since then, this versatile carbonic acid derivative has generally been used as fertilizer [1], diuretic [2], and amongst others it also has medical and laboratory applications [3]. Furthermore, urea has become a robust building block capable of forming persistent hydrogen-bond chains in a variety of environments, from solutions to gels and fibers, as well as crystals. [4] $N, N$-Disubstituted ureas can act as both hydrogen-bond donors by donating their two $\mathrm{NH}$ protons, and acceptors through the lone pairs of the $\mathrm{C}=\mathrm{O}$ group. The good complementarity between the two groups results in self-association forming robust one-dimensional hydrogen-bond chains. In addition, both ureas and thioureas - their thio analogues have long been exploited as anion binding groups in synthetic receptors by taking advantage of their ability to form strong hydrogen bonds to a wide variety of anions. [5]

The utilization of hydrogen bonding as an activation force has become a powerful tool in asymmetric organocatalysis. [6] In the mid-2000s, urea and thiourea were widely recognized as highly useful templates upon which powerful organocatalytic systems, [7] both mono- and bifunctional, can be constructed. [8] Increased acidity of thiourea [9] has been found to correlate with its increased catalytic activity than the urea has. [10] The earliest and most-enabling bifunctional catalysts were based on the thiourea scaffold, wherein the two-point hydrogen bond donor motif serves to organize and activate reaction substrates. [11, 12]

Squaramides, the bisamides of squaric acid, have been suggested as potent (thio)urea isosteres [13] with potential therapeutic benefits against a variety of diseases. [14] Moreover, since their first application in 2008 by Malerich et al. [15] chiral squaramides have become a dominant core in the bifunctional hydrogen bond catalyst field, [14] thanks to their higher acidity, and the significantly greater distance between the donor hydrogens (see Fig. 1).

In squaramides, the position of the two hydrogens are approximately $0.6 \AA$ further apart than in their thiourea analogues. Thus, they could serve as versatile activation units for dual hydrogen-bonding catalysts. [17] Quiñonero et al. [18] calculated the aromaticity of squaramide and its complexes with ammonium cations. They measured aromaticity by considering the aromatic stabilization energies, bond length and magnetic properties. Comparing to 


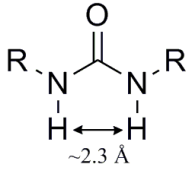<smiles>[R]Nc1c(N[14CH])c(=O)c1=O</smiles><smiles>[R]N1[13CH][13CH]N1[R]</smiles>

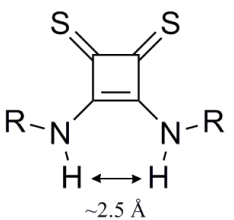

Fig. 1 Structure of (thio)urea, (thio)squaramide [14, 16]

squaramide, their results indicated that the squaramideammonium cation complex exhibits more aromatic character. [17] Exploiting their rigid planar structures, squaramides exhibit 10-50 times greater affinity for halides than thioureas do. [19]

It was shown that the remarkable hydrogen bond donor and acceptor character of squaramides can be explained by an enhancement in aromaticity upon hydrogen bond formation, that sets them apart from urea-based groups. [14] Therefore, squaramides have been utilized as alternatives to (thio)ureas in organocatalysis. [20, 21]

However, the self-aggregation of squaramides forming head-to-tail ladder networks through dual hydrogen-bonds leads to low solubility, hence to possible precipitation. [22] Despite their widespread use, the low solubility in nonpolar solvents and a limited ability to modulate the $\mathrm{p} K_{\mathrm{a}}$ of the donor hydrogens, restricts their performance in some reactions.

Replacement of even one of the carbonyl groups by thiocarbonyl leads to disruption of ladder formation and, as a result, improves solubility. Furthermore, this interconversion increases the acidity of the N-H bonds, in line with the case of urea and thiourea. According to computational and NMR titration methods thiosquaramides have found to be more acidic (4-5 $\mathrm{p} K_{\mathrm{a}}$ units) than the corresponding squaramides (see Table 1). [23]

X-Ray crystal structure of a bifunctional thiosquaramide showed smaller $\mathrm{H}-\mathrm{H}$ distance than in squaramides due to the steric and electronic repulsion of thiocarbonyl groups. Formation of ladder networks among thiosquaramides was not observed. [16]

In comparison to (thio)urea, the enhanced hydrogen-bonding interactions provided by thiosquaramide arise from the increase of aromaticity in the cyclic system upon formation of hydrogen bonds analogously to squaramide. [31, 32]
Table 1 Substituent effect on $\mathrm{p} K_{\mathrm{a}}$ values of (thio)urea and (thio) squaramide derivatives $^{\mathrm{a}}$

\begin{tabular}{|c|c|c|c|c|}
\hline Substituent & $\mathrm{R}_{-\mathrm{H}} \stackrel{\mathrm{O}}{\|_{\mathrm{H}^{-}}} \mathrm{R}$ & $\mathrm{R}_{\mathrm{H}^{\mathrm{N}}} \stackrel{\mathrm{S}}{\|_{\mathrm{H}^{-}}^{\mathrm{S}}}$ & ${ }_{\mathrm{H}}^{\mathrm{N}-\mathrm{R}}$ & ${ }_{\mathrm{H}}^{\mathrm{S}}$ \\
\hline$R=$ & $\begin{array}{l}18.7[24] \\
19.6[25]\end{array}$ & $\begin{array}{l}13.4[24] \\
13.5[25]\end{array}$ & $\begin{array}{c}12.5[26] \\
(11.7)[27]\end{array}$ & (7.3) [27] \\
\hline & $16.1[24]$ & 16.8 [28] & $\begin{array}{c}(9.8)[27] \\
(10.9)[29]\end{array}$ & (5.3) [27] \\
\hline $\mathrm{CF}_{3}$ & $13.8^{\mathrm{b}}[24]$ & 21.1 [28] & $\begin{array}{c}8.4[26] \\
(8.5)[27]\end{array}$ & (4.9) [27] \\
\hline & $17.6[23]$ & 13.7 [23] & ] & (7.7) [30] \\
\hline
\end{tabular}

${ }^{\mathrm{a}} \mathrm{p} K_{\mathrm{a}}$ Values are measured in DMSO. Parenthesis refers to values determined in acetonitrile-water 9:1.

${ }^{\mathrm{b}}$ Estimated value

Experiments and computations reveal that the increased acidity of thiosquaramides results in the formation of stronger hydrogen bonds than squaramide, urea, and thiourea do. [16, 20]

Assuming the existence of amide-like restricted rotation about the $\mathrm{C}-\mathrm{N}$ bond of squaramide, a bis-secondary squaramide containing two $\mathrm{C}-\mathrm{N}$ bonds might exist as mixtures of anti/syn conformers. This conformational bias has been investigated for several systems in solution by NMR. [17] According to X-ray crystal structure analysis of bis-secondary (thio)squaramides, the simultaneous participation of the two $\mathrm{NH}$ groups in a complex favors an extended anti / anti conformation (see Fig. 2) in squaramides, $[15,17]$ and in thiosquaramides [16] as well.

Recent developments of Rombola et al. [16, 33] in the preparation of thiosquaramides have resulted in a synthetic renaissance and have attracted considerable interest in the organocatalytic applications of a new family of hydrogen-bonding catalysts based on the thiosquaramide catalophore. Up to now, several variously substituted thiosquaramide derivatives were synthesized.

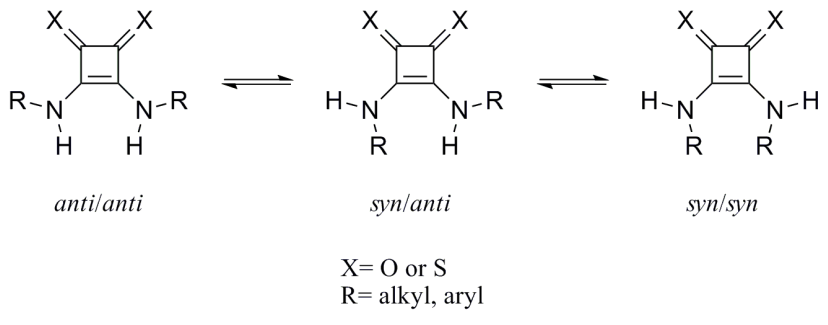

Fig. 2 Possible syn / anti conformers of (thio)squaramides 
In this review, a summary of these synthetic methods is presented considering the insertion of the thiocarbonyl group(s), and the reactivity of these compounds as well. Finally, a brief outlook on the application of thiosquaramide derivatives is given.

\section{Synthesis}

The first preparation of thiosquaramide B (see Scheme 1) was achieved in 1966 by Maahs and Hegenberg [34] in the reaction of $N, N^{\prime}$-dicyclohexylsquaramide with diphosphorus pentasulfide (Entry 1, Table 2) in dichloromethane.

Then, Seitz et al. $[35,36]$ and later Frauenhoff et al. [37] used tetraphosphorus decasulfide for the thionation of squaramides (Entry 2, Table 2). According to the experiments of Busschaert et al. [27], the application of Lawesson's reagent proved to be unsuccessful for the preparation of $\mathbf{B}$. Using tetraphosphorus decasulfide gave the expected product in low yields with a complex mixture of by-products, presumably due to impurities remaining from the preparation of the thionating reagent. Afterward, using the pyridine complex of tetraphosphorus decasulfide in acetonitrile, that was free from impurities, gave the appropriate thiosquaramides with medium yields (Entry 3, Table 2).

Later, Rombola et al. [16] published a second method for the formation of dithiosquaramides (B). Starting from dibutyl squarate, a half-squaramide $\mathbf{C}$ was synthesized, followed by thionation applying Lawesson's reagent (Entry 4, Table 2). In the last step, dithiosquaric half amide half ester (D) was converted into the appropriate dithiosquaramide through a second addition - elimination reaction using aralkyl amines.
This year as a continuation of their work, Rombola and Rawal [33] reported a new procedure in which dithiosquaramides (B) are prepared through the thionation of dicyclopentyl squarate (Entry 5, Table 2). In comparison to the easily decomposable dibutyl ester derivative (Entry 6, Table 2), dicyclopentyl dithiosquarate is a stable, easily accessible, and broadly modifiable scaffold (Entry 6, Table 2). Dithiosquaramides (both diaryl and alkylaryl) can be readily accessed from dicyclopentyl dithiosquarate via two separate addition - elimination reactions, similarly to the synthetic route that is widely applied for the synthesis of squaramides (Entries 7-9, Table 2). Due to the stability and reactivity of the dicyclopentyl derivative, dithiosquaric half amide half ester (D) intermediates can be easily prepared, purified, and fully characterized.

Additionally, this provides an opportunity to synthesize not only the symmetric dithiosquaramides, but the asymmetric ones also, where the nitrogens contain different substituents.

Finally, it is important to mention that monothionated squaramides can be synthesized as well. These methods apply the above-mentioned procedures, but in the thionation step half, or less than half, equivalent of thionating agent must be used. Seitz and Sutrisno [38] applied ethoxycarbonyl isothiocyanate for monothionation of squaramides (Entry 10, Table 2). Also, Rombola and Rawal [33] were able to prepare a partially thionated squaramide with complete regiocontrol as a result of their new methodology for the general synthesis of squaramides (Entries 11-13, Table 2).

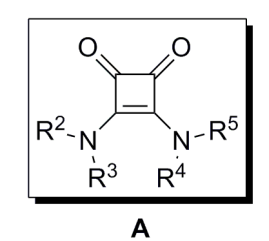

A
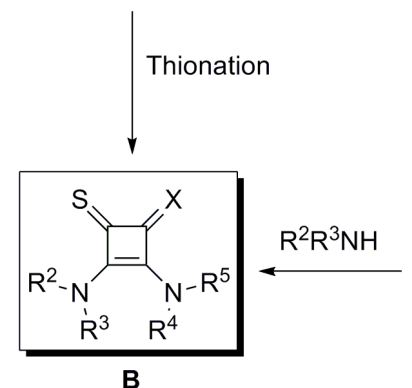

$R^{1}, R^{2}, R^{3}, R^{4}, R^{5}=H$, alkyl, aryl
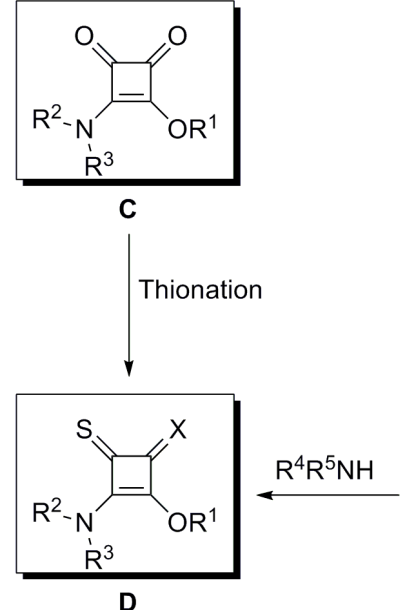
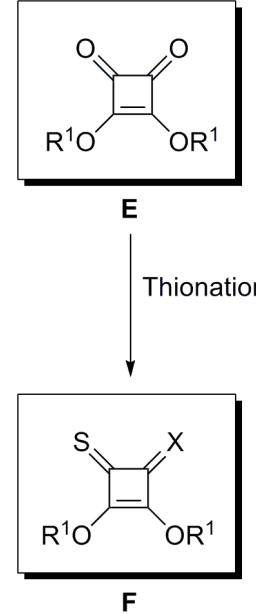

E Thionation $\downarrow$

$\mathrm{X}=\mathrm{O}, \mathrm{S}$

Scheme 1 Preparation of mono-, and dithio analogues of squarates and (half)squaramides 
Table 2 Synthesis of mono-, and dithio analogues of squarates and (half)squaramides

\begin{tabular}{lcccccc}
\hline Entry & Reaction & $\mathbf{R}^{\mathbf{1}}$ & Reagent & $\mathbf{X}$ & Solvent & Yield (\%) \\
\hline $\mathbf{1}$ & $\mathrm{A} \rightarrow \mathrm{B}$ & - & $\mathrm{P}_{2} \mathrm{~S}_{5}{ }^{a}$ & $\mathrm{~S}$ & $\mathrm{DCM}$ & $-[34]$ \\
$\mathbf{2}$ & $\mathrm{A} \rightarrow \mathrm{B}$ & - & $\mathrm{P}_{4} \mathrm{~S}_{10}{ }^{a}$ & $\mathrm{~S}$ & $\mathrm{DCM}$ & $36-72[35-37]$ \\
$\mathbf{3}$ & $\mathrm{A} \rightarrow \mathrm{B}$ & - & $\mathrm{P}_{4} \mathrm{~S}_{10} \cdot$ pyridine & $\mathrm{S}$ & $\mathrm{MeCN}$ & $37-66[27]$ \\
$\mathbf{4}$ & $\mathrm{C} \rightarrow \mathrm{D}$ & butyl & Lawesson's reagent & $\mathrm{S}$ & $\mathrm{DCM}$ & $67-83[16]$ \\
$\mathbf{5}$ & $\mathrm{E} \rightarrow \mathrm{F}$ & 3-pentyl, cyclopentyl & Lawesson's reagent & $\mathrm{O}, \mathrm{S}$ & $\mathrm{DCM}$ & $68-80[33]$ \\
$\mathbf{6}$ & $\mathrm{E} \rightarrow \mathrm{F}$ & butyl & Lawesson's reagent & $\mathrm{S}$ & $\mathrm{DCM}$ & $14[33]$ \\
$\mathbf{7}$ & $\mathrm{F} \rightarrow \mathrm{D}$ & cyclopentyl & alkyl or aryl amines & $\mathrm{S}$ & $\mathrm{DCM}$ & $52-79[33]$ \\
$\mathbf{8}$ & $\mathrm{D} \rightarrow \mathrm{B}$ & butyl or cyclopentyl & alkyl or aryl amines & $\mathrm{S}$ & $\mathrm{DCM}$ & $73-96[16,33]$ \\
$\mathbf{9}$ & $\mathrm{F} \rightarrow \mathrm{B}$ & cyclopentyl & alkyl or aryl amines & $\mathrm{S}$ & $\mathrm{DCM}$ & $30-86[33]$ \\
$\mathbf{1 0}$ & $\mathrm{A} \rightarrow \mathrm{B}$ & - & ethoxycarbonyl isothiocyanate & $\mathrm{O}$ & $\mathrm{MeNO}$ & $54-78[38]$ \\
$\mathbf{1 1}$ & $\mathrm{A} \rightarrow \mathrm{B}$ & - & $\mathrm{O}$ & $\mathrm{MeCN}$ & $26[30]$ \\
$\mathbf{1 2}$ & $\mathrm{F} \rightarrow \mathrm{D}$ & cyclopentyl & alkyl amine & $\mathrm{O}$ & $\mathrm{DCM}$ & $84[33]$ \\
$\mathbf{1 3}$ & $\mathrm{D} \rightarrow \mathrm{B}$ & cyclopentyl & alkyl amine & $\mathrm{O}$ & $\mathrm{DCM}$ & $57[33]$ \\
\hline
\end{tabular}

${ }^{a}$ This reagent is named as diphosphorus pentasulfide $\left(\mathrm{P}_{2} \mathrm{~S}_{5}\right)$ or as its dimer form, tetraphosphorus decasulfide $\left(\mathrm{P}_{4} \mathrm{~S}_{10}\right)$

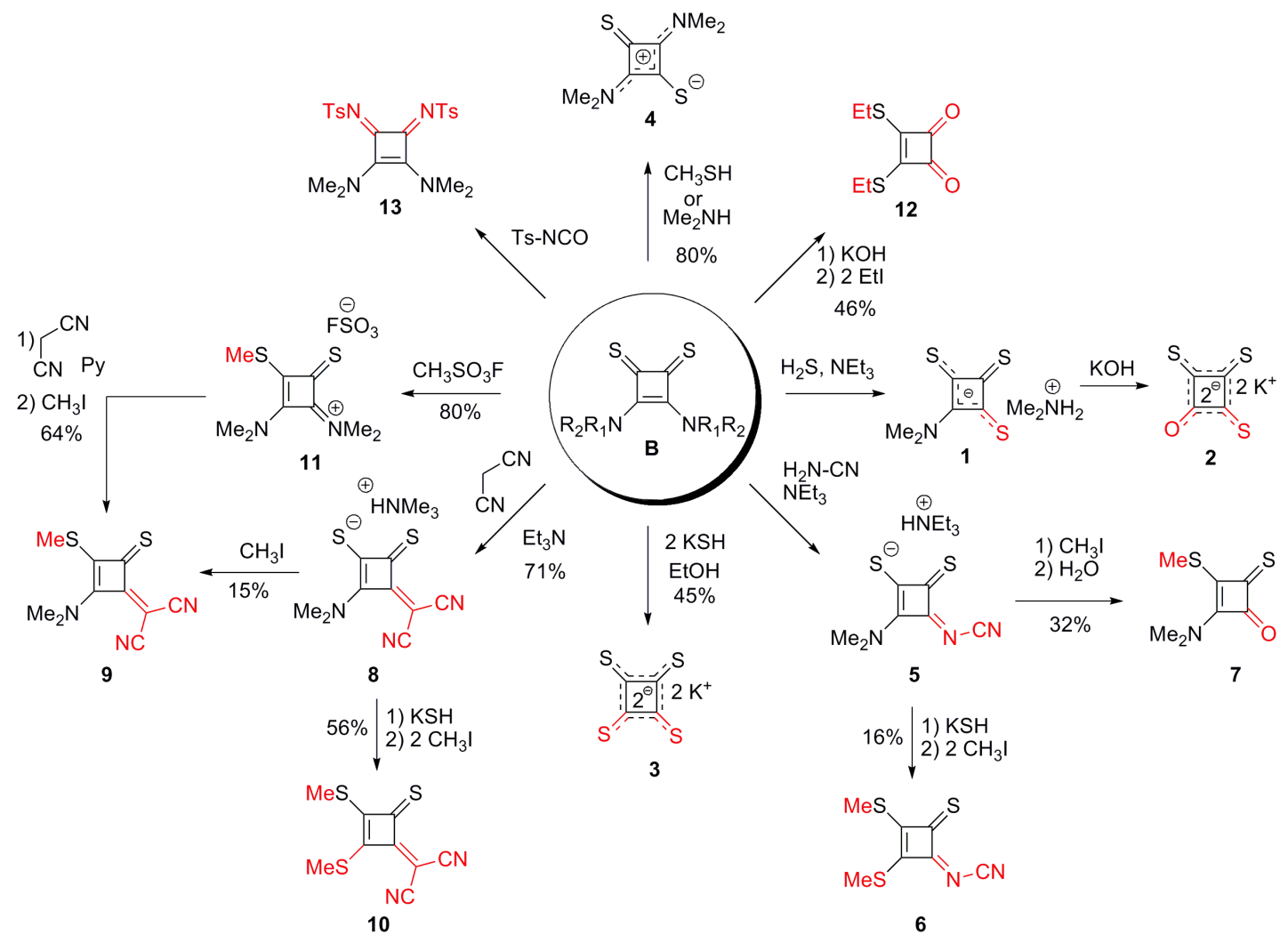

Scheme 2 Reactions of dithiosquaramides $\left(R_{1}=H ; R_{2}=B u\right.$; in other cases: $\left.R_{1}=R_{2}=M e\right)$

\section{Reactions}

Several reactions of dithiosquaramides have been reported, including the nucleophilic attacks on the vinylic carbon atom of the four-membered ring by $S$-, $O$ - and $N$-nucleophiles, and - as a result of the suitable leaving groups on the vinyl carbon of the cyclobutenedione system
- the successive displacement of the amino groups via an addition-elimination mechanism (Scheme 3).

Among reactions with $S$-nucleophiles, Seitz [39] reacted thiosquaramide $\mathbf{B}$ with hydrogen sulfide to gain adduct 1 (Scheme 2) with three adjacent sulfur functions, that can be converted into the potassium salt of 


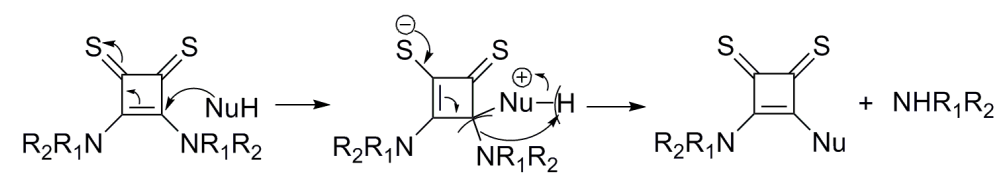

Scheme 3 General mechanism of nucleophilic addition-elimination reactions of thiosquaramides

trithiosquarate dianion 2 by subsequent hydrolysis with potassium hydroxide.

The tetrathiosquarate dianion $\mathbf{3}$ was obtained by Allmann et al. [40] as an air-stable orange-yellow hydrate. By heating it in air above $120^{\circ} \mathrm{C}$, the water of crystallization is removed and a dark violet, strongly hygroscopic crystal structure is formed, that can be readily reconverted into the hydrated salt when exposed to moisture.

The thermodynamically more stable thiosquaraines (4) can also be prepared with excellent yields by reacting dithiosquaramides (B) with nucleophiles such as dimethyl amine or methanethiol. [41]

$\mathrm{N}$-Nucleophilic cyanamide, in the presence of triethylamine followed by sulfohydrolysis readily transformed the dithiosquaramides $\mathbf{B}$ through intermediate $\mathbf{5}$ into the bis(methylthio)cyanamide derivative $\mathbf{6}$. The methylthio monooxo derivative 7 can be obtained after subsequent methylation and hydrolysis of intermediate 5. [42]

Arndt et al. [43] found that the malononitrile carbanion can act as a suitable $C$-nucleophile to replace at least one dimethylamino function in $\mathbf{B}$. The reaction product is the resonance-stabilized anion $\mathbf{8}$, which is isolable as the dimethylammonium salt. This intermediate (8) can be converted into the corresponding methylthio- (9) and bis(methylthio) (10) derivatives. Later, this research group developed another method for the preparation of methylthio thiosquaramide malonitrile 9. The iminium salt $\mathbf{1 1}$ is accessible in the reaction of $\mathbf{B}$ with "magic methyl" $\left(\mathrm{FSO}_{3} \mathrm{CH}_{3}\right)$. Next, 11 was reacted with the carbanion of malononitrile, followed by methylation to gain compound 9 with good yields. [43]

When the dithiosquaramide $\mathbf{B}$ was allowed to react with potassium hydroxide, a stable potassium salt was formed, that was converted into 12 after an ethylation step. [44]

Furthermore, the $\mathrm{C}=\mathrm{S}$ bond of dithiosquaramide $\mathbf{B}$ can be attacked by $p$-toluenesulfonyl isocyanate forming bisamidine $\mathbf{1 3}$ with high yields as a crystalline, colorless to yellowish solid. [45]

\section{Applications}

Considering the above mentioned structural properties, thiosquaramides are expected to be a "gold mine" for catalyst discovery. Rombola et al. [16] recognized this opportunity, and recently, they prepared the first chiral, bifunctional thiosquaramide derivatives. The catalyst performance was assessed by testing it in enantioselective conjugate addition of $N, N^{\prime}$-diphenylbarbituric acid (14) to $\beta$-nitrostyrene (15, see Scheme 4). The reactions gave the corresponding Michael adduct $\mathbf{1 6}$ with high conversion (>98\%) and high enantioselectivity (up to $99 \%$ ee) even with catalyst loadings as low as $0.05 \mathrm{~mol} \%$. The substituents of the amido nitrogens have significant effect on the catalytic performance of thiosquaramides 17-21.

Comparing the solubility of thiosquaramide $\mathbf{2 1}$ and that of squaramide $\mathbf{2 2}$ in toluene, the thio-analogue showed at least 30 times higher values. This can be explained by the lack of intermolecular hydrogen bonds to give stable ladder structures. [33]

Catalyst 22, the oxo-analogue of thiosquaramide $\mathbf{2 1}$ was also effective but gave lower enantioselectivity. The seemingly small difference observed in ee with these catalysts ( $95 \%$ vs. $97 \%$ ) corresponds to selectivity ratios of 40:1 and 70:1, respectively.

Moreover, Rombola and Rawal [33] evaluated the catalytic performance of thiosquaramides and squaramides in the conjugate addition of lawsone (23) to a $\beta, \gamma$-unsaturated $\alpha$-keto ester (24, Scheme 5) to give Michael adduct 25. All thiosquaramides (26-29) provided higher enantioselectivities than their oxo-analogues (30-33).

As a further catalytic application, the higher acidity of aryl thiosquaramides opens the possibility of their utilization as Bronsted acid catalysts. The former research group tested thiosquaramide $\mathbf{3 4}$ containing electron-withdrawing substituents in aza-Diels-Alder reaction between 2-silyloxydiene $\mathbf{3 5}$ and $N$-benzylidineaniline $\mathbf{3 6}$ (Scheme 6). [33]

This reaction afforded Diels-Alder adduct 37 with high $(77 \%)$ yield. In summary, the ability to dial up the 


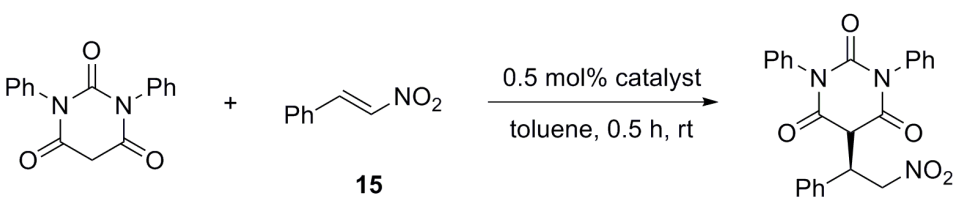

14

16

(>98\% conversion)<smiles>CN(C)[C@H]1CCCC[C@@H]1Nc1c(NC(C)(C)C)c(=S)c1=S</smiles>

17: $54 \%$ ee<smiles>CN(C)C1CCCCC1Nc1c(NC(C)(C)c2ccccc2)c(=S)c1=S</smiles>

$18: 45 \%$ ee<smiles>CN(C)C1CCCCC1Nc1c(NCc2ccccc2)c(=S)c1=S</smiles>

19: $88 \%$ ee<smiles>S=c1c(NCCc2ccccc2)c(NC2CCCCC2N2CCCCC2)c1=S</smiles>

20: $91 \%$ ee<smiles>[X]C1=C(NCc2ccccc2)C(N[C@@H]2CCCCC2N2CCCCC2)=C1[X]</smiles>

21: $X=S ; 97 \%$ ee 22: $X=O ; 95 \%$ ee

Scheme 4 Conjugate addition of barbituric acid (14) to $\beta$-nitrostyrene (15) catalyzed by bifunctional thiosquaramides.<smiles>O=C1C=C(O)C(=O)c2ccccc21</smiles>

23<smiles>CCOC(=O)C(=O)/C=C/c1ccccc1</smiles>

24

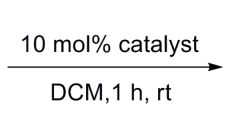
$\mathrm{DCM}, 1 \mathrm{~h}, \mathrm{rt}$<smiles>CCOC(=O)CC(=O)C1=C(O)C(=O)c2ccccc2C1=O</smiles>

25<smiles>[X]C1=C(Nc2cc([Y])cc([Y])c2)C([X])=C1NC1CCCCC1N(C)C</smiles>

26: $Y=H ; X=S ; 86 \%$ ee 27: $\mathrm{Y}=\mathrm{CF}_{3} ; \mathrm{X}=\mathrm{S} ; 82 \%$ ee 30: $Y=H ; X=O ; 64 \%$ ee 31: $\mathrm{Y}=\mathrm{CF}_{3} ; \mathrm{X}=\mathrm{O} ; 64 \%$ ee

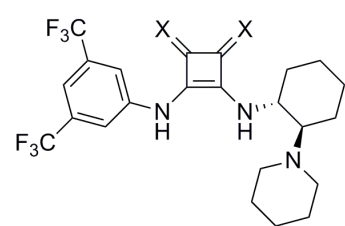

28: $X=S ; 94 \%$ ee 32: $\mathrm{X}=\mathrm{O} ; 85 \%$ ee

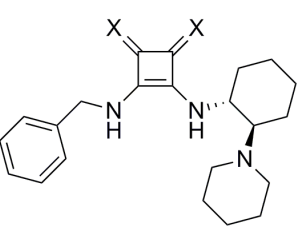

29: $X=S ; 80 \%$ ee

(in case of $X=S$ the ee is $9-22 \%$ higher, than in case of $X=0$ )

Scheme 5 Conjugate addition of lawsone (23) to a $\beta, \gamma$-unsaturated $\alpha$-keto ester (24) catalyzed by bifunctional thiosquaramides.

acidity of squaramides by converting one or both carbonyls to thiocarbonyls presents an opportunity to expand the catalyst's reaction footprint. Using modern tools of computational quantum chemistry a possible catalytic application of thiosquaramides was compared with analogous urea-, thiourea-, and squaramide catalysts in Diels-Alder cycloaddition of anthracene and nitrostyrene by $\mathrm{Lu}$ and Wheeler [20] The examined thiosquaramide-derived catalyst is predicted to promote formation of transitional states with the lowest energy barrier, while retaining the same high degree of enantioselectivity as the squaramides.

Besides their catalytic activity, dithiosquaramides have also been investigated as anion receptors $[6,27]$ that could be used in treatment of diseases characterized by incorrect anion transport. [7, 8] Elmes et al. [30] showed, that both mono-, and dithiosquaramides can be used as $\mathrm{pH}$-switchable chloride ion transporters. 

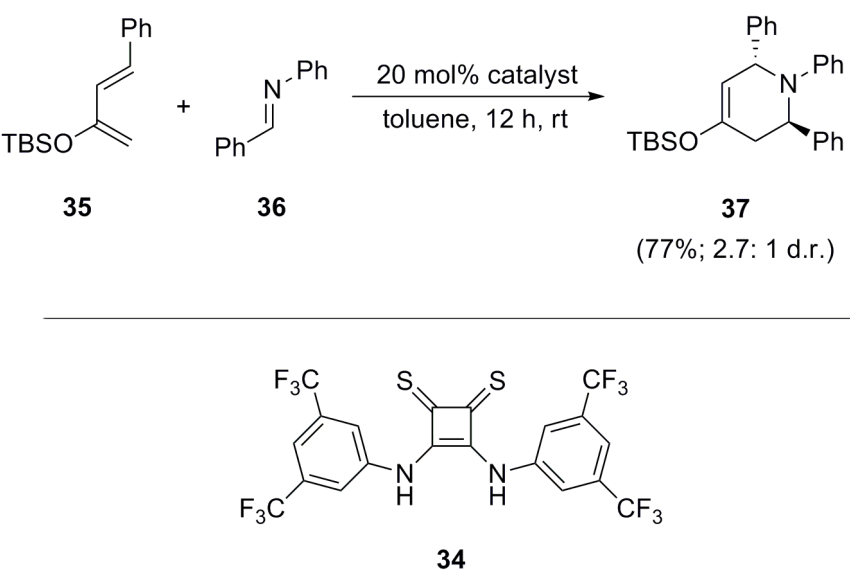

Scheme 6 Aza-Diels-Alder reaction using a thiosquaramide derivative (34) as a Bronsted acid catalyst

Finally, thiosquaramides can also form neutral 2:1 complexes with divalent metals $(\mathrm{Ni}, \mathrm{Pd}, \mathrm{Cu})$ that can lead to a possible application in coordination chemistry. [37]

\section{Conclusion}

We demonstrated the "rediscovery" of a more than five decades known thiosquaramide skeleton. During comparison of thiosquaramide with (thio)urea and squaramide, the structural origins of its increased aromaticity, acidity and greater solubility in non-polar solvents were discussed. For the preparation of thiosquaramides three main strategies were shown. These compounds can be obtained directly from squaramides, or starting from thiosquaric half amide half esters, and in the most effective approach, through the application of dicyclopentyl thiosquarate. Their reactivity can be categorized into two main types. Nucleophilic addition-elimination reaction can take place on the vinyl-, or on the thiocarbonyl carbon atoms, generating several (thio) squaramide derivatives. Thiosquaramides show promising

\section{References}

[1] Meessen, J. H., Petersen, H. "Urea", In: Bohnet, M. (ed.) Ullmann's Encyclopedia of Industrial Chemistry, 1st ed., Wiley-VCH, Weinheim, Germany, 2000. https://doi.org/10.1002/14356007.a27_333

[2] Hamilton Crawford, J., McIntosh, J. F. "The Use of Urea as a Diuretic in Advanced Heart Failure", Archives of Internal Medicine, 36(4), pp. 530-541, 1925.

https://doi.org/10.1001/archinte.1925.00120160088004

[3] Hama, H., Kurokawa, H., Kawano, H., Ando, R., Shimogori, T., Noda, H., Fukami, K., Sakaue-Sawano, A., Miyawaki, A. "Scale: a chemical approach for fluorescence imaging and reconstruction of transparent mouse brain", Nature Neuroscience, 14(11), pp. 1481-1488, 2011.

https://doi.org/10.1038/nn.2928 possibilities for their applications. Recently Rombola and Rawal [33] demonstrated the excellent enantioselective catalytic performance of chiral thiosquaramides, that is expected to further expand the reaction space in hydrogen bonding catalysis. Finally, like its oxo-analogue, mono-, and dithiosquaramides are recognized as suitable anion receptor core building blocks.

\section{Acknowledgement}

The project presented in this article was supported by the János Bolyai Research Scholarship of the Hungarian Academy of Sciences, the Servier-Beregi PhD Research Fellowship, and the Gedeon Richter's Talentum Foundation. "This work was supported by the ÚNKP-18-4-BME-270 New National Excellence Program of The Ministry of Human Capacities"

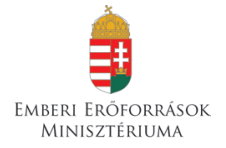

[4] Custelcean, R. "Crystal engineering with urea and thiourea hydrogen-bonding groups", Chemical Communications, (3), pp. 295-307, 2008. https://doi.org/10.1039/B708921J

[5] Hay, B. P., Firman, T. K., Moyer, B. A. "Structural design criteria for anion hosts: strategies for achieving anion shape recognition through the complementary placement of urea donor groups", Journal of the American Chemical Society, 127(6), pp. 1810-1819, 2005 .

https://doi.org/10.1021/ja043995k

[6] Yu, X., Wang, W. "Hydrogen-Bond-Mediated Asymmetric Catalysis", Chemistry - An Asian Journal, 3(3), pp. 516-532, 2008. https://doi.org/10.1002/asia.200700415 
[7] Dondoni, A., Massi, A. "Asymmetric Organocatalysis: From Infancy to Adolescence", Angewandte Chemie International Edition, 47(25), pp. 4638-4660, 2008.

https://doi.org/10.1002/anie.200704684

[8] Connon, S. J. "The Design of Novel, Synthetically Useful (Thio)urea-Based Organocatalysts", Synlett, 2009(3), pp. 354376, 2009.

https://doi.org/10.1055/s-0028-1087557

[9] Bordwell, F. G. "Equilibrium Acidities in Dimethyl Sulfoxide Solution", Accounts of Chemical Research, 21(12), pp. 456-463, 1988.

https://doi.org/10.1021/ar00156a004

[10] Parmar, D., Sugiono, E., Raja, S., Rueping, M. "Complete field guide to asymmetric BINOL-phosphate derived Brønsted acid and metal catalysis: history and classification by mode of activation, Brønsted acidity, hydrogen bonding, ion pairing, and metal phosphates", Chemical Reviews, 114(18), pp. 9047-9153, 2014. https://doi.org/10.1021/cr5001496

[11] Okino, T., Hoashi, Y., Takemoto, Y. "Enantioselective Michael reaction of malonates to nitroolefins catalyzed by bifunctional organocatalysts", Journal of the American Chemical Society, 125(42), pp. 12672-12673, 2003.

https://doi.org/10.1021/ja036972z

[12] Yoon, T. P., Jacobsen, E. N. "Highly Enantioselective ThioureaCatalyzed Nitro-Mannich Reactions", Angewandte Chemie International Edition, 44(3), pp. 466-468, 2005. https://doi.org/10.1002/anie.200461814

[13] Jin, C., Zhang, M., Wu, L., Guan, Y., Pan, Y., Jiang, J., Lin, C., Wang, L. "Squaramide-based tripodal receptors for selective recognition of sulfate anion", Chemical Communications, 49(20), pp. 2025-2027, 2013

https://doi.org/10.1039/c3cc00196b

[14] Storer, R. I., Aciro, C., Jones, L. H. "Squaramides: physical properties, synthesis and applications", Chemical Society Reviews, 40(5), pp. 2330-2346, 2011.

https://doi.org/10.1039/c0cs00200c

[15] Malerich, J. P., Hagihara, K., Rawal, V. H. "Chiral squaramide derivatives are excellent hydrogen bond donor catalysts", Journal of the American Chemical Society, 130(44), pp. 14416-14417, 2008.

https://doi.org/10.1021/ja805693p

[16] Rombola, M., Sumaria, C. S., Montgomery, T. D., Rawal, V. H. "Development of Chiral, Bifunctional Thiosquaramides: Enantioselective Michael Additions of Barbituric Acids to Nitroalkenes", Journal of the American Chemical Society, 139(15), pp. 5297-5300, 2017 https://doi.org/10.1021/jacs.7b01115

[17] Tomàs, S., Prohens, R., Vega, M., Rotger, M. C., Deyà, P. M., Ballester, P., Costa, A. "Squaramido-Based Receptors: Design, Synthesis, and Application to the Recognition of Tetraalkylammonium Compounds", The Journal of Organic Chemistry, 61(26), pp. 9394-9401, 1996.

https://doi.org/10.1021/jo9614147
[18] Quiñonero, D., Frontera, A., Suñer, G. A., Morey, J., Costa, A., Ballester, P., Deyà, P. M. "Squaramide as a binding unit in molecular recognition", Chemical Physics Letters, 326(3-4), pp. 247-254, 2000.

https://doi.org/10.1016/s0009-2614(00)00804-6

[19] Busschaert, N., Kirby, I. L., Young, S., Coles, S. J., Horton, P. N., Light, M. E., Gale, P. A. "Squaramides as Potent Transmembrane Anion Transporters", Angewandte Chemie International Edition, 51(18), pp. 4426-4430, 2012. https://doi.org/10.1002/anie.201200729

[20] Lu, T., Wheeler, S. E. "Origin of the Superior Performance of (Thio)Squaramides over (Thio)Ureas in Organocatalysis", Chemistry - A European Journal, 19(45), pp. 15141-15147, 2013. https://doi.org/10.1002/chem.201302990

[21] Mátravölgyi, B., Kovács, E., Hegedűs, L., Jászay, Z., Thurner, A., Deák, S., Erdélyi, Z., Pham, T. S., Gönczi, K., Sólyom, S., Töke, L., Faigl, F. "Synthesis and Application of New, Optically Active Compounds as Catalysts and Ligands in Enantioselective Reactions", Periodica Polytechnica Chemical Engineering, 59(1), pp. 38-50, 2015 https://doi.org/10.3311/PPch.7320

[22] Prohens, R., Portell, A., Font-Bardia, M., Bauzá, A., Frontera, A. "Experimental and theoretical study of weak intermolecular interactions in crystalline tertiary squaramides", Crystal Engineering Communications, 18(34), pp. 6437-6443, 2016. https://doi.org/10.1039/c6ce01299j

[23] Ho, J. M., Zwicker, V. E., Yuen, K. K. Y., Jolliffe, K. A. "Quantum Chemical Prediction of Equilibrium Acidities of Ureas, Deltamides, Squaramides, and Croconamides", The Journal of Organic Chemistry, 82(19), pp. 10732-10736, 2017. https://doi.org/10.1021/acs.joc.7b02083

[24] Jakab, G., Tancon, C., Zhang, Z., Lippert, K. M., Schreiner, P. R. "(Thio)urea Organocatalyst Equilibrium Acidities in DMSO", Organic Letters, 14(7), pp. 1724-1727, 2012.

https://doi.org/10.1021/o1300307c

[25] Bordwell, F. G., Ji, G. Z. "Effects of Structural Changes on Acidities and Homolytic Bond Dissociation Energies of the Hydrogen-Nitrogen Bonds in Amidines, Carboxamides, and Thiocarboxamides", Journal of the American Chemical Society, 113(22), pp. 8398-8401, 1991. https://doi.org/10.1021/ja00022a029

[26] Ni, X., Li, X., Wang, Z., Cheng, J.-P. "Squaramide Equilibrium Acidities in DMSO", Organic Letters, 16(6), pp. 1786-1789, 2014. https://oi.org/10.1021/o15005017

[27] Busschaert, N., Elmes, R. B. P., Czech, D. D., Wu, X., Kirby, I. L., Peck, E. M., Hendzel, K. D., Shaw, S. K., Chan, B., Smith, B. D., Jolliffe, K. A., Gale, P. A. "Thiosquaramides: pH switchable anion transporters", Chemical Science, 5(9), pp. 3617-3626, 2014. https://doi.org/10.1039/C4SC01629G

[28] Li, X., Deng, H., Zhang, B., Li, J., Zhang, L., Luo, S., Cheng, J.-P. "Physical Organic Study of Structure-Activity-Enantioselectivity Relationships in Asymmetric Bifunctional Thiourea Catalysis: Hints for the Design of New Organocatalysts", Chemistry A European Journal, 16(2), pp. 450-455, 2010. https://doi.org/10.1002/chem.200902430 
[29] Amendola, V., Fabbrizzi, L., Mosca, L., Schmidtchen, F.-P. "Urea-, Squaramide-, and Sulfonamide-Based Anion Receptors: A Thermodynamic Study", Chemistry - A European Journal, 17(21), pp. 5972-5981, 2011. https://doi.org/10.1002/chem.201003411

[30] Elmes, R. B. P., Busschaert, N., Czech, D. D., Gale, P. A., Jolliffe, K. A. "pH switchable anion transport by an oxothiosquaramide", Chemical Communications, 51(50), pp. 10107-10110, 2015. https://doi.org/10.1039/c5cc03625a

[31] Quiñonero, D., Frontera, A., Ballester, P., Deyà, P. M. "A theoretical study of aromaticity in squaramide and oxocarbons", Tetrahedron Letters, 41(12), pp. 2001-2005, 2000. https://doi.org/10.1016/s0040-4039(00)00084-8

[32] Quiñonero, D., Prohens, R., Garau, C., Frontera, A., Ballester, P., Costa, A., Deyà, P. M. "A theoretical study of aromaticity in squaramide complexes with anions", Chemical Physics Letters, 351(1-2), pp. 115-120, 2002. https://doi.org/10.1016/s0009-2614(01)01295-7

[33] Rombola, M., Rawal, V. H. "Dicyclopentyl Dithiosquarate as an Intermediate for the Synthesis of Thiosquaramides", Organic Letters, 20(3), pp. 514-517, 2018. https://doi.org/10.1021/acs.orglett.7b03549

[34] Maahs, G., Hegenberg, P. "Syntheses and Derivatives of Squaric Acid", Angewandte Chemie International Edition, 5(10), pp. 888-893, 1966. https://doi.org/10.1002/anie.196608881

[35] Seitz, G., Morck, H., Mann, K., Schmiedel, R. "Schwefelanaloga von Quadratsäure-1,2- und -1,3-bisamiden 10. Mitt. Ueber Polycarbonyl-Verbindungen" (Sulfur analogues of squaric acid 1,2- and 1,3-bisamides 10. Paper about polycarbonyl compounds), Chemiker-Zeitung, 98, pp. 459-460, 1974. (in German)

[36] Seitz, G., Mann, K., Schmiedel, R. "Ein neuer Syntheseweg zu Quatratsäure-1,3-dithion-bis-amiden 13. Mitt. Ueber Polycarbonylverbindungen" (A new synthetic route to squaric acid-1,3-dithione-bis-amides 13. Paper about polycarbonyl compounds), Chemiker-Zeitung, 9, p. 332, 1975. (in German)

[37] Frauenhoff, G. R., Takusagawa, F., Busch, D. H. "Transition metal complexes of the cis-dithiosquaramide ligand family", Inorganic Chemistry, 31(19), pp. 4002-4007, 1992.

https://doi.org/10.1021/Ic00045a027

[38] Seitz, G., Sutrisno, R. "ChemInform Abstract: Polycarbonyl Compounds. 23. Ethoxycarbonyl isothiocyanate as a reagent for introducing thioxo functions in squaric acid amides", Chemischer Informationsdienst, 10(11), p. 176, 1979. https://doi.org/10.1002/chin.197911176

[39] Seitz, G. "Thioxocarbon Dianions $\mathrm{C}_{\mathrm{n}} \mathrm{S}_{2}{ }^{2-}$ and Other SulfurContaining Derivatives of Deltic and Squaric Acid", Phosphorus, Sulfur, and Silicon and the Related Elements, 43(3-4), pp. 311347, 1989. https://doi.org/10.1080/10426508908040292

[40] Allmann, R., Debaerdemaeker, T., Mann, K., Matusch, R., Schmiedel, R., Seitz, G. "Polycarbonylverbindungen, XVI. Darstellung und Struktur des Schwefelanalogons des
Quadratsäure-Dianions $\mathrm{K}_{2}\left[\mathrm{C}_{4} \mathrm{~S}_{4}\right] \cdot \mathrm{H}_{2} \mathrm{O}$ " (Polycarbonyl compounds, $\mathrm{XVI}$. Representation and structure of the sulfur analogue of squaric acid dianions $\mathrm{K}_{2}\left[\mathrm{C}_{4} \mathrm{~S}_{4}\right] \cdot \mathrm{H}_{2} \mathrm{O}$ ), Chemische Berichte, 109(6), pp. 2208-2215, 1976. (in German) https://doi.org/10.1002/cber.19761090627

[41] Matusch, R., Schmiedel, R., Seitz, G. "Polycarbonylverbindungen, XXV. Versuche zur Synthese des Tetrathioquadratsäuredimethylesters" (Polycarbonyl compounds, XXV. Attempts to synthesize the tetrathiosquaric acid dimethyl esters), Liebigs Annalen der Chemie, 1979(5), pp. 595-604, 1979. (in German) https://doi.org/10.1002/jlac.197919790502

[42] Kämpchen, T., Seitz, G., Sutrisno, R. "Polycarbonylverbindungen, XXXIII) Ein neuer schwefelhaltiger "Pseudooxokohlenstoff" der C4-Reihe mit Cyanimin-Funktion" (Polycarbonyl compounds, XXXIII1) A new sulfur-containing "pseudooxocarbon" of the C4 series with cyanimine function), Chemische Berichte, 114(10), pp. 3448-3455, 1981. (in German) https://doi.org/10.1002/cber.19811141026

[43] Arndt, G., Kämpchen, T., Schmiedel, R., Seitz, G., Sutrisno, R. "Polycarbonylverbindungen, XXIX. Schwefelhaltige Dicyanmethylen - "Pseudooxokohlenstoff" - Anionen" (Polycarbonyl compounds, XXIX. Sulfur-containing dicyanomethylene - "pseudooxocarbon" anions), Liebigs Annalen der Chemie, 1980(9), pp. 1409-1418, 1980. (in German) https://doi.org/10.1002/jlac.198019800909

[44] Seitz, G., Mann, K., Schmiedel, R., Matusch, R. "Polycarbonylverbindungen, XXIV. Gemischte "Oxothioxokohlenstoffe" aus Amiden und Thioamiden der Quadratsäure" (Polycarbonyl compounds, XXIV. Mixed "oxothioxocarbons" of amides and thioamides of squaric acid), Chemische Berichte, 112(3), pp. 990-999, 1979. (in German) https://doi.org/10.1002/cber.19791120321

[45] Seitz, G., Schmiedel, R., Mann, K. "Polycarbonylverbindungen, 19. Mitt. Synthese und Solvolysereaktionen tosylsubstituierter Quadratsäurebisamidine" (Polycarbonyl Compounds, 19. Paper Synthesis and solvolysis reactions of tosyl-substituted squaric acid bisamidines), Archiv der Pharmazie, 310(7), pp. 549-559, 1977. (in German) https://doi.org/10.1002/ardp.19773100705

[46] Gale, P. A., Davis, J. T., Quesada, R. "Anion transport and supramolecular medicinal chemistry", Chemical Society Reviews, 46(9), pp. 2497-2519, 2017. https://doi.org/10.1039/c7cs00159b

[47] Busschaert, N., Gale, P. A. "Small-molecule lipid-bilayer anion transporters for biological applications", Angewandte Chemie International Edition, 52(5), pp. 1374-1382, 2013. https://doi.org/10.1002/anie.201207535

[48] Gale, P. A., Pérez-Tomás, R., Quesada, R. "Anion Transporters and Biological Systems", Accounts of Chemical Research, 46(12), pp. 2801-2813, 2013. https://oi.org/10.1021/ar400019p 